\title{
Review \\ Gender and Sanitation: Women's Experiences in Rural Regions and Urban Slums in India
}

\author{
Wren Vogel ${ }^{1}$, Christina D. Hwang ${ }^{2}$ and Sangchul Hwang ${ }^{3, *}$ \\ 1 Sustainability Studies Program, Department of Sociology, Texas State University, San Marcos, TX 78666, USA; \\ rlv33@txstate.edu \\ 2 The Liberal Arts and Science Academy, Austin, TX 78721, USA; christina.d.hwang@gmail.com \\ 3 Civil Engineering Program, Ingram School of Engineering, Texas State University, San Marcos, TX 78666, USA \\ * Correspondence: sanhwang@txstate.edu; Tel.: +1-512-245-3858
}

Citation: Vogel, W.; Hwang, C.D.; Hwang, S. Gender and Sanitation: Women's Experiences in Rural Regions and Urban Slums in India. Societies 2022, 12, 18. https:/ / doi.org/10.3390/soc12010018

Academic Editor: Gregor Wolbring

Received: 20 November 2021

Accepted: 28 January 2022

Published: 30 January 2022

Publisher's Note: MDPI stays neutral with regard to jurisdictional claims in published maps and institutional affiliations.

Copyright: (c) 2022 by the authors. Licensee MDPI, Basel, Switzerland. This article is an open access article distributed under the terms and conditions of the Creative Commons Attribution (CC BY) license (https:// creativecommons.org/licenses/by/ $4.0 /)$.

\begin{abstract}
Without adequate sanitation facilities, environmental, social, and health risks are common and worsen as the state of sanitation stagnates. Vulnerable groups, specifically women, are unequally affected by poor sanitation. Attitudes towards and perceptions of gender and menstruation have created a health and social discrepancy between women and men. Women must undergo additional obstacles when practicing proper sanitation and managing menstruation. This article utilizes the sanitation insecurity measure to assess the lived experience of women in rural and urban India. This article also discusses accounts of women's experiences managing menstruation in both the rural regions and urban slums of India and discusses the social implications of the state of sanitation. Examining the issue of sanitation by focusing on menstruation and the dichotomy of men's and women's experiences with sanitation and hygiene will indicate that achieving gender equity requires sanitation to be viewed as a human rights, social justice, and education issue.
\end{abstract}

Keywords: gender; health; WASH; menstrual hygiene management; sanitation insecurity

\section{Introduction}

Without reliable and accessible sanitation, individuals are exposed to an array of social, psychological, and physical risks. Over half of the world's population, over four billion people, only have access to sanitation facilities that do not treat human waste, two billion of those people lack a toilet, and over 670 million do not have access to a toilet at all [1]. It has been estimated that $6.3 \%$ of deaths globally could be prevented by improving water, sanitation, and hygiene [2]. Examining the level of sanitation within developing countries elucidates how impactful inadequate sanitary conditions are to both the physical and the social environment. Focus on this issue has been placed in several countries within Southeast Asia, including Indonesia, the Philippines, Malaysia, and India.

Over one billion people live in India, and nearly half of the population commonly practices open defecation, creating a major health hazard to both the human population and the physical environment of the country. In 2015, 568 million people practiced open defecation due to a lack of access to toilets. That number had been drastically reduced to 450 million in 2019 since the onset of Swachh Bharat Mission or the Clean India Campaign [1]. Created by the Prime Minister of India, the Clean India Campaign focused on mass scale behavior change (sanitation fairs and direct involvement from schools and communities), construction of house-owned and community-owned toilets, monitoring of toilet construction and usage [3]. However, thousands of people in India still do not have access to hygienic sanitation facilities. Open defecation is most common in rural regions as these areas do not have underground piping systems, and many households do not have the fiscal ability to construct toilets.

International intervention has helped sanitation in India's local communities greatly. After the implementation of UNICEF'S WASH (Water, Sanitation and Hygiene) campaign 
in over 100 developing countries, over five million USD have been accepted from the private sector to mitigate the issue. A total of 25,000 people are reported to have become open defecation free, and 175,000 people have access to safe water [4]. However, the Asian Development Bank estimates the financial requirements to provide household toilets in rural areas at 4.7 million USD and 3.3 million USD in urban areas [5]. In addition to more funds needing to be allocated to sanitation development, the completion of public infrastructure projects must be enforced. According to The World Bank, 1.2 trillion USD are spent on infrastructure projects, including the construction of toilets connected to an underground sewer system, in low- and middle-income countries, but $30 \%$ of those projects are uncompleted [6]. Sanitation infrastructure requires steady maintenance and often does not receive proper oversight. Latrine overflow or break-down leads more people to resort to open defecation. Incompletion of infrastructure projects and inconsistent maintenance need to be addressed to decrease the number of people who practice open defecation and therefore to improve the state of sanitation.

The sociological implications of open defecation have been underexamined as many beliefs and predispositions held toward toilets and sanitation are misconstrued, specifically when gender and femininity are involved. In rural India, inadequate sanitation harms the physical environment, causes millions of deaths, and unequally affects vulnerable populations such as women, children, and those with physical disabilities [1,7]. India had the highest infant mortality rate of all countries in 2015, with the leading causes of post neonatal mortality being pneumonia ( $9 \%$ to $12 \%$ ) and diarrhea ( $8 \%$ to $9 \%$ ), both of which are correlated with sanitation [8]. It has been estimated that $21 \%$ of the deaths that occur are related to non-potable water sources [4]. According to The World Health Organization, 88\% of diarrhea cases around the world are the result of inadequate drinking water, sanitation, or hygiene.

This article examines the literature on women's experiences with sanitation and menstruation in India. Through an evaluation of articles on sanitation in urban slums and rural areas, this article will elucidate that the rural regions of India are not the only areas stricken by sanitation insecurity. The urban slums are also facing this issue as millions of people, specifically women, struggle to meet their sanitary needs. The goal of this article is to increase discourse on remediating the sanitation issues that millions face in developing countries and encouraging a reevaluation of the apportionment of funds from the private sector by discussing the events that have led to the state of sanitation within rural areas and urban slums of India. This evaluation and application of sanitation insecurity will focus on the problems associated with poor sanitation within the physical environment, the socio-cultural environment, and the lack of education, and how each relates to gender. The authors of this conceptual paper recognize that representation in navigating sanitation and menstruation is not confined by the parameters of gender identity. All people who menstruate experience sanitation differently than those who do not. Using the word women to describe those who menstruate is not a disregard for men who menstruate or those that identify as non-binary who menstruate, instead this conceptual paper seeks to emphasize the attributes connected to gender, not gender itself.

\section{Sanitation}

Initially, research on sanitation and health focused only on the links between pathogen and contaminant exposure and infectious disease [9], with diseases associated with sanitation problems categorized as water-related, water-washed, or water-borne [10]. Focusing solely on pathogen exposure does not quantify the extent of sanitation insecurity as a human rights issue. Addressing sanitation as a human rights issue transitions the focus from physical solutions, such as building more toilet blocks or constructing toilets in homes below the poverty line, to changed governmental frameworks that are set in place so that sanitation is available to everyone [11]. Proper sanitation should not be dependent on factors out of an individual's control. It is an inherent right and a common good. Understanding the lived experience of people residing in the urban and rural areas of India will 
aid in the understanding that sanitation insecurity is a non-linear issue. It is fragmented, and its effects are experienced differently based on economic class, geographic location, and gender.

\subsection{Improved and Unimproved Sanitation}

The term "toilet insecurity", when operable toilets are unavailable [12], has been applied to encapsulate the issue of sanitation and bathroom hygiene. An environment with subpar or "unimproved" sanitation either lacks a toilet or has a toilet that does not separate human excrete from human contact. It is a bucket or a hanging toilet if not piped to a sewer system such as a septic tank [9]. A shared facility of any kind, no facilities, or usage of an open field or bush is also considered as unimproved sanitation. Improved sanitation is categorized as having a toilet connected to a piped sewer system including a septic tank or having a composting toilet [13]. It is estimated that 4.2 billion people, around 55\% of the world's population, lack access to improved and safely managed sanitation and over 494 million people practiced open defecation in 2020 [14]. According to [13], 28\% of the total Indian population does not have access to improved sanitation, making up over $6 \%$ of the urban population and around $40 \%$ of the rural population (Figure 1). More than half of the world population that practices open defecation live in rural India $[1,15]$.

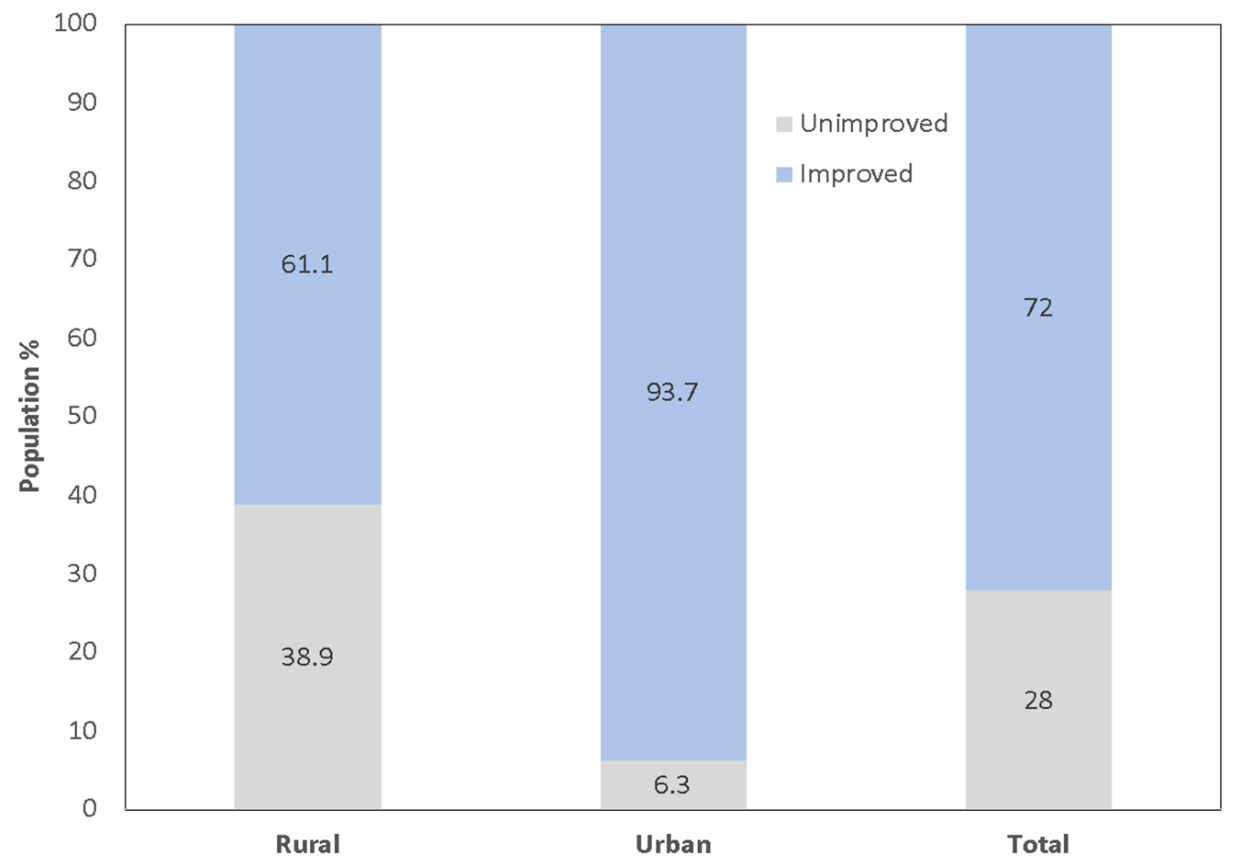

Figure 1. Sanitation percentage levels in India. Data retrieved from [13].

The measurement of improved versus unimproved sanitation does not consider that ownership of a toilet does not equate to the toilet being used. A study conducted in rural Odisha found that among the houses that had toilets, a third of the home inhabitants did not use it. Instead, they practiced open defecation. In this instance, the most common reasons for open defecation are preference, the toilet not being fully operable, inconvenience, lack of privacy, or the toilet being used for another purpose such as storage [15]. Religious beliefs, miseducation on hygiene, and habit are other reasons for open defecation being commonly practiced. Open defecation is also popular because some view that time as an opportunity to socialize with friends or as an activity that makes them feel independent because they get to choose the location [16].

Although having access to a toilet is considered improved sanitation, the level of sanitation in the household may still incur compromising health effects. This leads to the inference that measuring the number of individuals with access to improved sanitation could potentially be inaccurate. There are other factors not encompassed within the 
Improved versus Unimproved measure that are not included that influence toilet usage and hygiene. Developing an accurate metric to determine the level, unimproved or improved, of sanitation in individuals' homes will better quantify this issue. Sanitation insecurity furthers the limited terms of improved versus unimproved sanitation by accounting for the multiple constraints that limit individuals, specifically women, from having access to proper sanitation facilities.

\subsection{Sanitation Insecurity}

Sanitation insecurity is defined as "insufficient and uncertain access to a socio-cultural and social environment that respect and respond to the sanitation needs of individuals, and to adequate physical spaces and resources for independently, comfortably, safely, hygienically, and privately urinating, defecating, and managing menses with dignity at any time of day or year as needs arise in a manner that prevents fecal contamination of the environment and promotes health" [17]. As this definition encompasses several elements that play a role in the gendered experience, it allows for the adaptation of the term to be applied as a reference for future studies. This definition is expanding this area of study as it covers the multiple dimensions that influence women's experiences with sanitation. The definition is flexible in that it can be applied to a variety of living environments, but it leaves sanitation needs up for interpretation. The allocation of funds may be appointed to areas outside of sanitation improvement if governing bodies deem that the country's present sanitation needs are being met. In most developing countries, people who menstruate are often not included in decision-making groups. An example of this comes from rural Odisha in India, where women lack money, confidence, and power, resulting in their exclusion from decision making [17]. Underrepresented and placed in a diminutive position, women are unable to speak on behalf of themselves and their experience with sanitation as policies set in place reproduce sexual divisions [18]. Women's social mobility is limited due to the attitudes and perceptions of both men and women on menstruation and femininity in general. Gender has played a large role in making sanitation an individualized problem that is supported or unsupported by a person's physical location. Addressing the socio-cultural environment is a key portion of the definition of sanitation insecurity and will require a restructuring of educational systems regarding menstruation and a deconstruction of misconceptions perpetuated by cultural beliefs. When first defined by Caruso et al. [17], the term, sanitation insecurity, was applied to describe the state of sanitation in Odisha, India. However, in other regions of India, such as within urban slum environments, this term is applicable to describe the sanitary state as well. Through the application of this term, the multiple aspects that have an influence on the quality of sanitation an individual is exposed to will be deconstructed and evaluated as they relate to the conditions with urban slum environments, and an expanded evaluation of rural regions will be provided.

\section{Gender and Sanitation}

Gender discrimination in science and health journals has led to the unequal representation of women. Gender bias and androcentric scholarly research on health has recently undergone fragmentation as the institutionalized patriarchal influence has been recognized. Such an effort is the topic of sanitation insecurity as it recognizes that men and women do not share the same experience and men cannot serve as a gold standard on which to base sanitation and health. Should an androcentric view be used to address this issue, women will continue to be disproportionately affected by sanitation insecurity.

Historically, menstrual health has been neglected. Focus on women's health has been placed on issues of sexual and reproductive health, such as sexually transmitted diseases, contraceptives, and family planning [19]. This androcentric approach to women's health succumbs to the constraints of traditional gender roles. Levinson [20] states, "sexist belief systems foster social control by blaming the victim, create a gender-related invalid through labeling, and keep women from achieving educationally and occupationally" (428). This 
statement is fully supported by empirical evidence and contextual studies on women in India.

In most cases, women are more affected by the lack of adequate sanitary conditions. The lack of access to proper sanitation is described as an "affliction of the vulnerable and marginalized", and women, "more often than men", reap the consequences of inadequate sanitation [18]. As a gendered affliction, sanitation insecurity affects women, like men, regarding hygienic maintenance and methods of defecation; however, women undergo additional obstructions to maintain their hygiene during menstruation. Additionally, India is the world's most dangerous country for women. This conclusion was made based on three benchmarks: (1) the danger women face in traditional and cultural practices, (2) the risk of sexual violence and harassment, and (3) the danger of domestic servitude, sex slavery, forced labor, and human trafficking [21]. The danger women face is the result of the cultivation of misogyny through the limitation of women's educational opportunities, perpetuation of limiting gender roles, and misrepresentation of menstruation as a form of weakness that calls for social exclusion. To fully address and understand sanitary insecurity as a gendered issue, its impacts must be contextualized across the rural, urban slum, and inner urban regions of India. Managing menstrual health is a large facet of sanitation insecurity as a whole and requires attention when addressing the issue of inadequate sanitation.

\section{Menstrual Hygiene Management}

Normal menstruation is defined as the cyclical bleeding process that occurs between menarche and menopause [22]. Although it is a process with no cultural or geographic bounds, stigmas and perceptions associated with menstruation vary based on location. Traversing through many arenas of sociological influence, one can find that this definition is interpreted differently across the globe as seen by some people understanding menstruation to be a biologically normal and healthy process and others believing it to be a signifier of impurity and shame. The act of managing menstruation varies based on the resources an individual has access to, the cultural beliefs held where they live, and physical limitations.

Menstrual hygiene management (MHM) is a social justice issue within the arena of public health [23]. Menstrual health, which includes the accessibility of menstrual products, accurate information on menstruation, and access to safe, hygienic bathroom facilities, should be examined as a promoter of overall health [24]. MHM is limited to using what is easily available for use and is bound by the social constraints of an individual's community. For example, those living in rural regions are less likely to have menstrual products available, as markets and manufacturers are likely far away. Moreover, the feminine hygiene products (FHPs) available may be unaffordable. Many sanitary products cost between five and 12 rupees (0.08 and 0.20 USD) [25], but for the 800 million people living on less than two USD per day in India, this price is too expensive. MHM is an important factor of health, as poor MHM can increase the likelihood of reproductive tract infections [26]. In recent years, menstrual health has joined the global agenda [22] as focus has been placed on the lived experience of women in low- and middle-income countries and their access to sanitary products, education, toilets, and clean water.

As a country with diverse cultural and economic regions, the experience of women in India varies from the inner urban regions to the rural areas. Because there is such a variety of cultures, social stigmas, and levels of access to resources within the country, no singular product or direction of aid could benefit every woman in the country. MHM has been placed under the wing of WASH (Water, Sanitation and Hygiene), and understandably so, but its implications reach beyond access to clean water and private sanitary spaces. According to the WHO, WASH includes drinking water and sanitation services, solid waste management, stormwater management, and the source of water. Behaviors and attitudes towards sanitation are also included within the WASH sector. MHM falls within the overlap of sanitation, health, and human rights, so that through an examination of the lived experience of women within the inner urban regions, urban slums, and rural 
areas, a better understanding of MHM and the physical and social constraints women must overcome and adapt to will be generated.

\section{Assessment of Sanitation and Menstrual Hygiene Management}

\subsection{Urban Regions}

Megacities, such as Mumbai, Delhi, and Kolkata, are constantly increasing in population density. This leads to massive spatial growth and increased demand for and pressure on sanitation services throughout the area [27]. During periods of rapid population or economic growth, environmental degradation and socio-economic inequality are not the primary areas of focus [28]. This further widens the gap between urban poor and urban non-poor in terms of sanitation insecurity. Nearly all the urban non-poor have access to adequate sanitation services while less than half of the urban poor have equal access [27]. The environmental conditions of urban slums in India are abysmal as the lack of wastewater treatment facilities causes sewage to pollute surface water sources. As most people rely on surface water for daily usage, contamination from inadequate sanitation services causes severe health problems such as diarrhea. It has been recorded that $70 \%$ of surface water sources in India are polluted [29] and therefore are unfit for consumption. Sanitation insecurity leads to a cycle of a multitude of economic, health, and social problems that will persist unless improvements in sanitation insecurity are made (Figure 2). The needs of women, children, and those with physical disabilities must be met when making improvements to sanitation and fully represented when examining how inadequate sanitation affects an area.

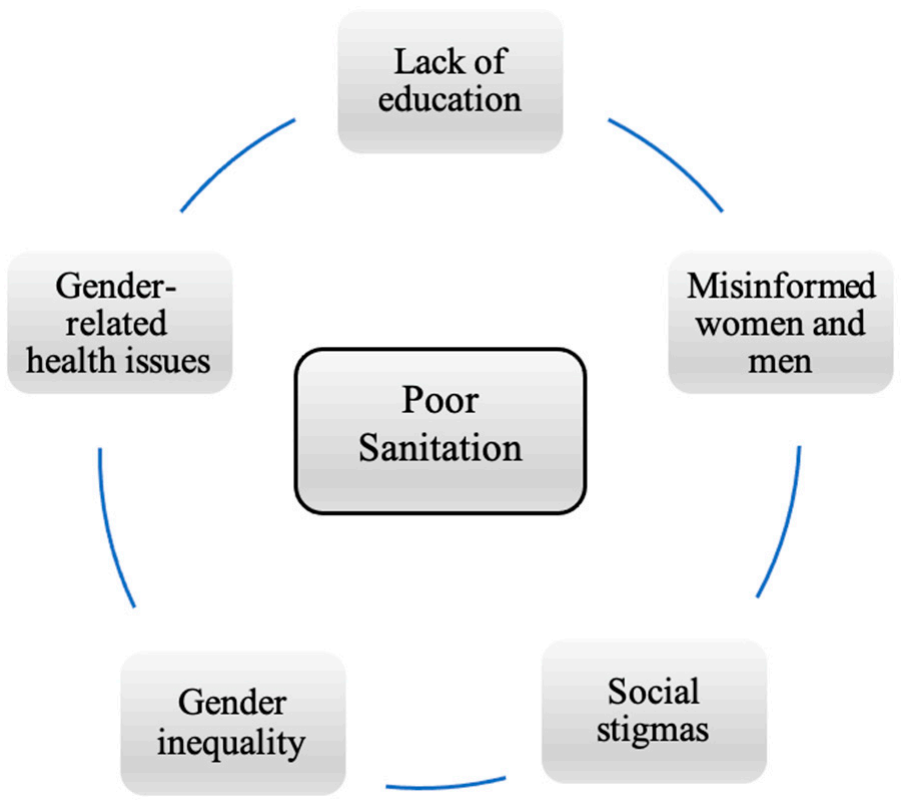

Figure 2. Events Causing Poor Sanitation.

\subsection{Slums}

Slums are defined as "residential areas where dwellings are in any respect unfit for human habitation by reasons of dilapidation, overcrowding, faulty arrangements and designs of such buildings, narrowness or faulty arrangement of streets, lack of ventilation, light, sanitation facilities or any combination of these factors which are detrimental to safety, health and morals" [30]. Slum-dwellers lack at least one of the following: durable housing that provides protection from weather events, protection from eviction, sufficient living spaces (no more than three people sharing a room), easy access to potable water at an affordable price, and access to adequate sanitary facilities (private or public toilets) [31]. According to UNICEF and the WHO [1], identified slums are categorized as having at least 300 people in an unhygienic compact area with inadequate infrastructure and no sanitary or drinking water facilities and which are sites of severe environmental injustice. 
Without proper sewage facilities, unsanitary water and fecal matter make their way into river bodies and slum communities commonly receive the blame. Decision-making bodies hold an anti-poor bias, placing preference on improving the environment of the formal residential areas while slum-dwellers often receive no aid or improvement. In 2003, a slum settlement in Delhi near the Yamuna River was demolished under the pretext of polluting the river with sewage water even though the court lacked any evidentiary support of the settlement contributing to the river pollution [32]. Factories that often employ many of the slum residents emitted airborne and water contaminants [27] but did not receive the same scrutiny as slum communities in their contribution to polluting surface water. The association between mortality rates, geographic location, and socioeconomic status is apparent when examining the environment of the slums compared to formal residential areas. Infants born within urban poor areas have higher mortality rates than those within the rural poor and urban non-poor areas [33].

Single-issue institutions and urban development bodies construct sanitation systems, such as toilet blocks and water supply infrastructure, but leave additional maintenance to municipal corporations [34]. The inability of municipal corporations to properly maintain the sanitary facilities leads them to become unhygienic and unusable. Toilet blocks are constructed but are not regularly cleaned or maintained by any authority, which leads to those in informal settlements frustrated at their lack of upkeep and many women preferring open defecation over using the unclean toilets even though this puts them in a more vulnerable position [35]. Toilet block construction is often haphazard, with a limited water supply and no drainage access. It has been observed that toilet blocks face severe sanitary and mechanical issues within three months of their construction [36]. Due to the lack of drainage, fecal matter enters the streets and contaminates water sources and soil. The areas surrounding the toilet blocks become heavily contaminated from the overflowing toilets and from open defecation. Fecal matter contamination causes ailments such as diarrhea, trachoma, intestinal worms, and salmonella [37]. In 2018, seven people were killed every day from contaminated water in India, and over 35,000 people were diagnosed with water-borne diseases [37]. According to the CDC [38,39], diarrheal diseases are the fourth largest cause of death in India, falling below heart disease, chronic obstructive pulmonary disease, and stroke. Cities do have maintenance groups that are intended to clean the toilet blocks and maintain drainage, but the maintenance staff often disregard the toilet blocks in the urban slums due to bureaucracies in municipal corporations and no sense of ownership in local governmental bodies [36].

\section{MHM in Slums}

Overcrowding combined with unhealthy living conditions results in an increased probability of contracting illness and experiencing sexual violence while practicing MHM. Several studies have been conducted on the living conditions of women in urban slums [36,40-43] that contextualize both the physical and the social constraints faced while managing menstruation.

In the slums of Delhi, where most of the population falls below the poverty line, menarche is viewed as a woman reaching full physical maturity and gaining the ability of having children. In Delhi, menstruation is viewed as the release of ganda khoon (dirty blood) and is correlated with impurity and untouchability. A woman interviewed by [40] discusses the perception of men on menstruation; "If a man even touches a menstruating woman, he becomes ritually impure". This social exclusion leads to the isolation of women educationally and professionally.

Shame and confusion are common themes among women and young girls reaching menarche. Common statements from menstruating women are "I've become untouchable" or "I'm sitting apart" [40]. This shame comes from the bodily differences of men and women and the subordinated position of women [44] and femininity in terms of gender and sexuality. The perceived untouchability and impurity segregate not only a woman in social settings but also in the home, where some women are unable to attend to their regular 
duties due to potential contamination of a pure space. This causes menstruation to affect not only the menstruator but also each member in the home, as women are most likely to provide the food and to clean for the family but are unable to touch anything someone else could touch. The sense of impurity connected to menstruation is common among Muslim and Hindu people and in Western society. In both Islam and Hinduism, women are unable to visit holy places or touch religious texts while they are menstruating [40] and traditional Christianity views menstruation as an unclean punishment for the original sin of eating the forbidden fruit [44]. The impact of this physiologically natural occurrence spans across several spheres of a woman's life but is not an impediment strictly in developing countries. Additionally, menopause, puberty, menstruation, and pregnancy were once viewed as conditions contributing to a woman's frailty [20]. In recent decades, however, the direction of research has positioned women in an empowered and equitable position simply as humans who deserve human rights.

Although misinterpreted, menstruation is handled with care and in the cleanest available manner by women in urban slums due to its correlation with infectious disease. Most women use old cloths as pads due to its availability and low price. Around $70 \%$ of women cannot afford sanitary pads [41] or purchase new cloth [40], so that slum residents and women in rural areas use rags from old clothes as these materials are immediately available and can be reused. The problem with reusing old clothes is that they are often improperly cleaned or cannot be dried fully [45]. According to [41], the lack of sanitation facilities leads to increased susceptibility to urinary tract and reproductive tract infections, dropping out from school, and absenteeism from work.

\subsection{Rural Areas}

Over half of the world's population that live in rural areas have unimproved sanitation. The more geographically isolated an area is, the less available sanitation services and sanitary pads are. The government can begin constructing more sanitary facilities to overcome the physical constraints faced in rural areas, but this does not mean they will be used [15]. In rural areas, open defecation is preferred and more common, meaning that the construction of facilities is often of no use. The rural environment's combined waste from open defecation and single-use sanitary pads or rags poses many health concerns. It has been estimated that over 12.3 billion disposable sanitary pads are used every year in India, and it takes between 500 and 800 years for a single disposable sanitary pad to decompose [46].

However, the detrimental environmental consequences of sanitation insecurity regarding menstrual health management have not been addressed by governmental entities. Indeed, the Governments of India's Total Sanitation Campaign has only focused on building toilets in rural homes below the poverty line. Since the beginning of the Total Sanitation Campaign, 90 million household toilets have been built [15]. However, these toilets were only built in some homes in rural areas. Households that were not categorized as below the poverty line were not given aid. Most of the focus on improving the sanitary conditions in rural areas has been placed on building more toilets and sanitary facilities [37], but actual sanitary improvements cannot be made unless the rural population uses the facilities provided. In rural areas, the physical constraints of sanitation insecurity include the inaccessibility of sanitary pads and the lack of toilets in some households. However, with governmental programs building toilets and facilities in rural regions to overcome this constraint, the main issue stopping individuals from using improved sanitation are ingrained social habits and cultural and social stigmas associated with toilets and menstruation.

\subsubsection{MHM in Rural Areas}

The stigmas attached to femininity and womanhood have made menstruation a social concept instead of a biologically natural process [44]. Improving education on sanitation and menstruation could change the social norms and social shame [10] experienced by women. Socioeconomic status has the biggest effect on which material a woman has access 
to while menstruating. In rural areas, most families are among the lower economic class and thus their access to resources is limited to reusing clothes and old rags. In fact, $90 \%$ of women in rural areas utilize clothing items to serve as a pad during menstruation. However, it is found that as women age, their likelihood of using more hygienic MHM practices increases [45]. This could be correlated to women of ages between 20 and 30 likely being married, thus increasing their ability to purchase sanitary pads. Dependence on a husband for a source of income adds to the social constraints women face while menstruating and in general. At an early age, young girls are limited to what their family can provide for them. Often, however, the stigmas associated with menstruation inhibit young girls from sharing with their families that they are menstruating, leaving them on their own to find something to serve as a sanitary pad.

The lack of education and social constraints inflicted on girls and boys at an early age creates a non-inclusive environment that leads girls to have to navigate the physiologically normal, yet sometimes terrifying, experience of menarche by themselves. As menstruation is equated to impurity and shame, young girls are often ostracized by their community and thus fall behind educationally and socially. Due to the lack of education on how menstruation works, some boys are misled to believe that menstruation is shameful, occurs weekly, or is a form of disease [47]. Since men hold most of the representative power and decision-making ability, they can further spread misconceptions on menstruation that lead to lackluster efforts to improve sanitation for women and continue the gender disparity within the health system $[47,48]$. Men's lack of knowledge on MHM has made it an issue of gender inequality, thus restricting the social mobility of women and girls [48]. To address this discrepancy, proper education on menstruation needs to come from schools and the taboo nature of the topic needs to be eliminated. In many instances, boys are curious about menstruation and want to know more about the process [47], but the extent of education given in schools is limited and can be unsuccessful in articulating menstruation as a biological process and not as a degrading socio-cultural indicator of womanhood.

\subsubsection{Correlations among Toilet Availability, Poverty, and Rural Population Percentages}

In India, rural areas have higher poverty, as shown in Figure 3, where there is a significant $(p<0.05)$, weakly positive Pearson's correlation $(\mathrm{r}=0.374)$ between the percentages of poverty and rural population. Moreover, toilet availability showed a substantial $(p<0.05)$, moderately negative correlation with both poverty and rural percentages: the less the toilet availability, the greater the poverty $(r=-0.553)$ and the less toilets are available for the rural population $(\mathrm{r}=-0.536)$. As Elledge et al. (2018) reported, these significant correlations indicate that provision of WASH or sanitation infrastructure (e.g., toilets) designed to accommodate MHM, including access to menstrual hygiene products and safe handling and disposal of used menstrual products, is critical to support women's health and dignity, especially in low- and middle-income countries [49]. However, it should be noted that toilet usage needs to be motivated among the public as more than $40 \%$ of the population in India still engage in open defecation in 2015 [50] despite large-scale government efforts to expand sanitation coverage [15]. 

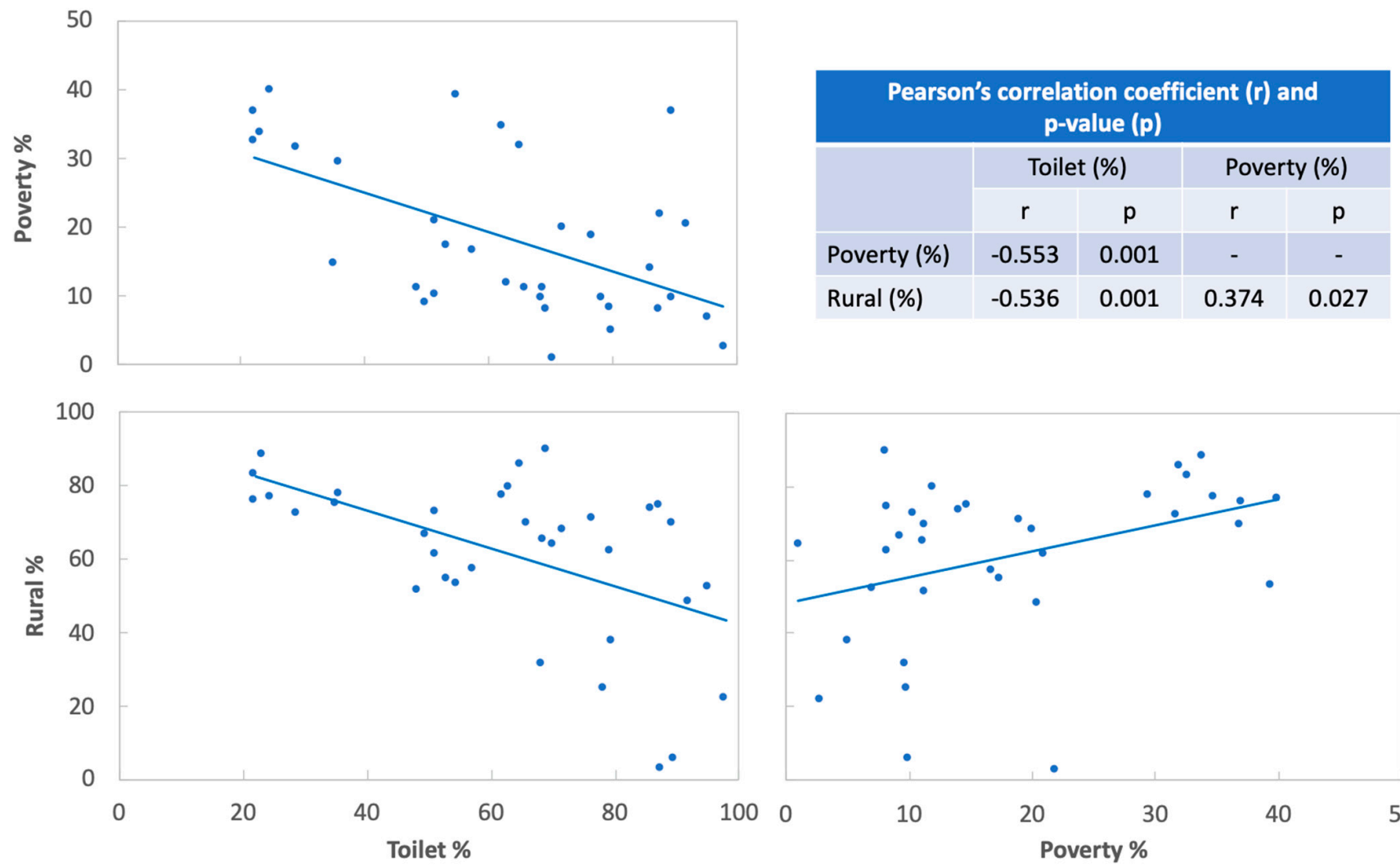

Figure 3. Pearson's correlations among toilet availability, poverty, and rural population percentages in India. Data are from 2011 Census of India [30,51,52].

\section{Conclusions and Recommendations}

There are many factors that influence the level of sanitation an individual receives. The layout of this paper allows for the reader to develop an understanding of the concepts of sanitation insecurity, MHM, and the limitations of international support prior to delving into the multi-faceted topic of sanitation. This paper discusses the experiences of individuals living in the urban slums and within the rural regions of India by drawing from the literature and deriving information from interviews, governmental reports, and news stories from each region. Not only does this paper discuss sanitation as a whole and how both women and men are put at risk by unsanitary living conditions, but it also emphasizes the experience of women as they attempt to manage menstruation in the most healthful way, despite issues and limitations they face from having an inadequate water supply and unhygienic conditions. This paper expands the application of sanitation insecurity to describe not only the state of sanitation within some rural areas of India, but also the conditions within urban slum environments.

Sanitation insecurity is not a symptom of poverty. It is a barrier to the reduction of poverty and development. Progress has been made on the state of sanitation and health in India in recent decades but work still needs to be done. Misconceptions need to be addressed by increasing the level of education boys and girls receive in schools and within their households. Properly educating males on menstruation will increase the social mobility of females, which would prevent them from being set behind educationally or socially. Then, they will have more power in making decisions regarding sanitation and their health. Focusing on education through dismantling false information that is perpetuated by cultural beliefs will positively affect the state of sanitation. Examining the state of India's sanitation using the definition of sanitation insecurity allows for a holistic approach to the problem and a potential holistic solution as well. Using this approach to assess sanitation will address the limitations that one may experience when attempting to manage one's hygiene. The gendered aspect of sanitation is also recognized 
in this approach. As more attempts are made to increase the sanitation level in India, application of this approach will result in a well-rounded assessment of and solution to the issue. As attention to and understanding of menstruation rises, social stigmas and taboos surrounding it will begin to dissolve. It must be noted that solutions will vary within the social landscape, as the origin of the issue is socially induced. Improvement must be made soon, or the damaged physical environment of India will no longer be able to support the growing population.

There is a need for continued research and action towards improving the state of sanitation and the quality of MHM in both developing and developed countries. Although this paper focuses on women's experiences with sanitation in rural regions and the urban slums of India, the sanitation insecurity measure could be used as a framework to examine other countries. A well-rounded framework such as the sanitation insecurity measure supports a holistic perspective as it examines not only the availability of sanitary facilities, but also the effect that gender, social structures, community awareness, and culture have on the quality of sanitation within an area.

Author Contributions: Conceptualization, C.D.H., S.H. and W.V.; methodology, S.H. and W.V.; formal analysis, S.H.; investigation, W.V.; resources, W.V., C.D.H. and S.H.; writing-original draft preparation, W.V. and C.D.H.; writing-review and editing, S.H., C.D.H. and W.V.; supervision, S.H.; project administration, S.H.; funding acquisition, S.H. All authors have read and agreed to the published version of the manuscript.

Funding: This research was funded by the Provost's Office at Texas State University, grant number 9000002728/2000011022.

Institutional Review Board Statement: Not applicable.

Informed Consent Statement: Not applicable.

Data Availability Statement: Data used in Figure 3 are from 2011 Census of India [30,51,52].

Conflicts of Interest: The authors declare no conflict of interest.

\section{References}

1. UNICEF; WHO. State of the World's Sanitation: An Urgent Call to Transform Sanitation for Better Health, Environments, Economies and Societies; United Nations Children's Fund and the World Health Organization: New York, NY, USA, 2020.

2. Prüss-Üstün, A.; Bos, R.; Gore, F.; Bartram, J. Safer Water, Better Health-Costs, Benefits and Sustainability of Interventions to Protect and Promote Health; World Health Organization: Geneva, Switzerland, 2008.

3. Government of India. Committed to Building a Swachh and Swasth Bharat. Swachh Bharat Mission-Grameen, 2020. Available online: https:/ / swachhbharatmission.gov.in/SBMCMS/about-us.htm (accessed on 1 November 2021).

4. Zhang, D. 10 Facts About Sanitation in India. 2020. Available online: https://borgenproject.org/sanitation-in-india/ (accessed on 21 July 2021).

5. Reddy, V.; Kumar, R.J. Financing the WASH Sector in India Cost of Provision and Budget Allocations; WASHCost Working Paper No. 12; Centre for Economic and Social Studies: Hyderabad, India, 2011.

6. Rasul, I.; Rogger, D. Management of Bureaucrats and Public Service Delivery: Evidence from the Nigerian Civil Service. Econ. J. 2017, 128, 413-446. [CrossRef]

7. Kumar, A. Discrepancies in Sanitation Statistics of Rural India. Econ. Polit. Wkly. 2015, 50, $13-15$.

8. Liu, L.; Chu, Y.; Oza, S.; Hogan, D.; Perin, J.; Bassani, D.G.; Ram, U.; Fadel, S.A.; Pandey, A.; Dhingra, N.; et al. National, Regional, and State-Level All-Cause and Cause-Specific Under-5 Mortality in India in 2000-15: A Systematic Analysis with Implications for the Sustainable Development Goals. Lancet Glob. Health 2019, 7, e721-e734. [CrossRef]

9. Caruso, B.; Clasen, T.; Yount, K.; Cooper, H.; Hadley, C.; Haardörfer, R. Assessing Women's Negative Sanitation Experiences and Concerns: The Development of a Novel Sanitation Insecurity Measure. Int. J. Environ. Res. Public Health 2017, 14, 755. [CrossRef] [PubMed]

10. Mauro, B.M. An Evaluation of Rural Sanitation in India. Master's Thesis, The University of Texas, Austin, TX, USA, 2015.

11. SDC. Sanitation: A Human Rights Imperative; Swiss Agency for Development and Cooperation SDC: Bern, Switzerland, 2008.

12. O'Reilly, K. From Toilet Insecurity to Toilet Security: Creating Safe Sanitation for Women and Girls. WIREs Water 2015, 3, 19-24. [CrossRef]

13. CIA. The World Factbook. Available online: www.cia.gov/the-world-factbook/ (accessed on 11 March 2021).

14. UN-Water. Summary Progress Update 2021: SDG 6-Water and Sanitation for All. Volume 2021; UN-Water: Geneva, Switzerland, 2021. 
15. Barnard, S.; Routray, P.; Majorin, F.; Peletz, R.; Boisson, S.; Sinha, A.; Clasen, T. Impact of Indian Total Sanitation Campaign on Latrine Coverage and Use: A Cross-Sectional Study in Orissa Three Years Following Programme Implementation. PLoS ONE 2013, 8, e71438. [CrossRef] [PubMed]

16. Bhatt, N.; Budhathoki, S.S.; Lucero-Prisno, D.E., III; Shrestha, G.; Bhattachan, M.; Thapa, J.; Sunny, A.K.; Upadhyaya, P.; Ghimire, A.; Pokharel, P.K. What motivates open defecation? A qualitative study from a rural setting in Nepal. PLoS ONE 2019, 14, e0219246.

17. Caruso, B.A.; Clasen, T.F.; Hadley, C.; Yount, K.M.; Haardörfer, R.; Rout, M.; Dasmohapatra, M.; Cooper, H.L. Understanding and Defining Sanitation Insecurity: Women's Gendered Experiences of Urination, Defecation and Menstruation in Rural Odisha, India. BMJ Glob. Health 2017, 2, e000414. [CrossRef]

18. Swaminathan, P. State and Subordination of Women. Econ. Polit. Wkly. 1987, 22, WS34-WS39.

19. Sommer, M.; Sahin, M. Overcoming the Taboo: Advancing the Global Agenda for Menstrual Hygiene Management for Schoolgirls. Am. J. Public Health 2013, 103, 1556-1559. [CrossRef]

20. Levinson, R. Sexism in Medicine. Am. J. Nurs. 1976, 76, 426-431. [CrossRef] [PubMed]

21. Aikat, D.; Beamer, B.; Marron, M.B. Misogyny across Global Media; Lexington Books: Lexington, KY, USA, 2021.

22. Critchley, H.O.D.; Babayev, E.; Bulun, S.E.; Clark, S.; Garcia-Grau, I.; Gregersen, P.K.; Kilcoyne, A.; Kim, J.-Y.J.; Lavender, M.; Marsh, E.E.; et al. Menstruation: Science and Society. Am. J. Obstet. Gynecol. 2020, 223, 624-664. [CrossRef] [PubMed]

23. Sommer, M.; Hirsch, J.S.; Nathanson, C.; Parker, R.G. Comfortably, Safely, and without Shame: Defining Menstrual Hygiene Management as a Public Health Issue. Am. J. Public Health 2015, 105, 1302-1311. [CrossRef] [PubMed]

24. Medina-Perucha, L.; Jacques-Aviñó, C.; Valls-Llobet, C.; Turbau-Valls, R.; Pinzón, D.; Hernández, L.; Canseco, P.B.; López-Jiménez, T.; Lizarza, E.S.; Feliu, J.M.; et al. Menstrual Health and Period Poverty among Young People Who Menstruate in the Barcelona Metropolitan Area (Spain): Protocol of a Mixed-Methods Study. BMJ Open 2020, 10 , e035914. [CrossRef] [PubMed]

25. Rodriguez, L. The Indian Government May Soon Make Period Products More Affordable. 2019. Available online: https: //www.globalcitizen.org/en/content/india-to-control-prices-of-sanitary-pads/ (accessed on 2 August 2021).

26. Das, P.; Baker, K.K.; Dutta, A.; Swain, T.; Sahoo, S.; Das, B.S.; Panda, B.; Nayak, A.; Bara, M.; Bilung, B.; et al. Menstrual Hygiene Practices, WASH Access and the Risk of Urogenital Infection in Women from Odisha, India. PLoS ONE 2015, 10, e0130777. [CrossRef] [PubMed]

27. Chaplin, S.E. Indian Cities, Sanitation and the State: The Politics of the Failure to Provide. Environ. Urban. 2011, 23, 57-70. [CrossRef]

28. Dilay, A.; Diduck, A.; Patel, K. Environmental Justice in India: A Study on Environmental Impact Assessment and Environmental Courts. In Proceedings of the IAIA18 Durban International Convention Center, Durban, South Africa, 16-18 May 2018.

29. ADRI. India Water Facts. Available online: https://www.adriindia.org/adri/india_water_facts (accessed on 11 June 2021).

30. Census of India. Primary Census Abstract for Slum; Office of the Registrar General and Census Commissioner: New Delhi, India, 2011.

31. UN-HABITAT. State of the World's Cities 2006/2007; United Nations Human Settlements Programme: New York, NY, USA, 2007.

32. Ghertner, D.A. Analysis of New Legal Discourse behind Delhi's Slum Demolitions. Econ. Polit. Wkly. 2008, 43, 57-66.

33. Bradley, D.J.; Stephens, C.; Harpham, T.; Cairncross, S.; Al, E. A Review of Environmental Health Impacts in Developing Country Cities; The World Bank: Washington, DC, USA, 1992.

34. Chaplin, S.E. Cities, Sewers and Poverty: India's Politics of Sanitation. Environ. Urban. 1999, 11, 145-158. [CrossRef]

35. McFarlane, C. Sanitation in Mumbai's Informal Settlements: State, “Slum”, and Infrastructure. Environ. Plann. A 2008, 40, 88-107. [CrossRef]

36. Burra, S.; Patel, S.; Kerr, T. Community-Designed, Built and Managed Toilet Blocks in Indian Cities. Environ. Urban. 2003, 15, 11-32. [CrossRef]

37. Clasen, T.; Boisson, S.; Routray, P.; Cumming, O.; Jenkins, M.; Ensink, J.H.J.; Bell, M.; Freeman, M.C.; Peppin, S.; Schmidt, W.-P. The Effect of Improved Rural Sanitation on Diarrhoea and Helminth Infection: Design of a Cluster-Randomized Trial in Orissa, India. Emerg. Themes Epidemiol. 2012, 9, 7. [CrossRef] [PubMed]

38. Kumar, C. Polluted Water Killed 7 Every Day in 2018. Available online: https://timesofindia.indiatimes.com/india/pollutedwater-killed-7-every-day-in-2018/articleshow/69996658.cms (accessed on 28 May 2021).

39. CDC Global Health-India. Available online: www.cdc.gov/globalhealth/countries/india/ (accessed on 11 October 2021).

40. Garg, S.; Sharma, N.; Sahay, R. Socio-Cultural Aspects of Menstruation in an Urban Slum in Delhi, India. Reprod. Health Matters 2001, 9, 16-25. [CrossRef]

41. Jacob, I.; Khanna, M.; Yadav, N. Beyond Poverty: A Study of Diffusion \& Adoption of Feminine Hygiene Products among Low Income Group Women in Mumbai. Procedia Soc. Behav. Sci. 2014, 148, 291-298.

42. van Eijk, A.M.; Sivakami, M.; Thakkar, M.B.; Bauman, A.; Laserson, K.F.; Coates, S.; Phillips-Howard, P.A. Menstrual Hygiene Management among Adolescent Girls in India: A Systematic Review and Meta-Analysis. BMJ Open 2016, 6, e010290. [CrossRef]

43. Vishwakarma, D.; Puri, P.; Sharma, S.K. Interlinking Menstrual Hygiene with Women's Empowerment and Reproductive Tract Infections: Evidence from India. Clin. Epidemiol. Glob. Health 2021, 10, 100668. [CrossRef]

44. Sitar, P. Female Trouble: Menstrual Hygiene, Shame and Socialism. J. Gend. Stud. 2017, 27, 771-787. [CrossRef]

45. Anand, E.; Singh, J.; Unisa, S. Menstrual Hygiene Practices and Its Association with Reproductive Tract Infections and Abnormal Vaginal Discharge among Women in India. Sex. Reprod. Healthc. 2015, 6, 249-254. [CrossRef] 
46. Sambyal, S.S.; Henam, S.; Tariang, F. Is Green Menopause Possible? Available online: https://www.downtoearth.org.in/blog/ waste/is-green-menstruation-possible--64796 (accessed on 10 June 2021).

47. Mason, L.; Sivakami, M.; Thakur, H.; Kakade, N.; Beauman, A.; Alexander, K.T.; van Eijke, A.M.; Laserson, K.F.; Thakkar, M.B.; Phillips-Howard, P.A. 'We Do Not Know': A Qualitative Study Exploring Boys Perceptions of Menstruation in India. Reprod. Health 2017, 14, 174. [CrossRef]

48. Gundi, M.; Subramanyam, M.A. Curious Eyes and Awkward Smiles: Menstruation and Adolescent Boys in India. J. Adolesc. Health 2020, 85, 80-95. [CrossRef]

49. Elledge, M.F.; Muralidharan, A.; Parker, A.; Ravndal, K.T.; Siddiqui, M.; Toolaram, A.P.; Woodward, K.P. Menstrual Hygiene Management and Waste Disposal in Low and Middle Income Countries-A Review of the Literature. Int. J. Environ. Res. Public Health 2018, 15, 2562. [CrossRef]

50. Leong, C. Narratives of sanitation: Motivating toilet use in India. Geoforum 2020, 111, 24-38. [CrossRef]

51. Census of India. Availability and Type of Latrine Facility: 2001-2011. Available online: https://censusindia.gov.in/2011census / hlo/Data_sheet/India/Latrine.pdf (accessed on 12 December 2021).

52. Census of India. Provisional Population Totals. Available online: https://censusindia.gov.in/2011-prov-results/paper2/data_ files/india/paper2_1.pdf (accessed on 11 June 2021). 